\title{
BUILDING ETHICS REGIMES: CAPABILITIES, OBSTACLES AND SUPPORTS FOR PROFESSIONAL ETHICAL DECISION-MAKING
}

\author{
HUGH BREAKEY*
}

\section{INTRODUCTION}

Every day, people make moral decisions, and perform actions based on those decisions. These occurrences' quotidian nature can obscure the fact that many distinct processes must be successfully navigated for principled moral action to take place. Agents need to be sensitive to situational factors that call for moral consideration; they need to be capable of reflecting on those features to arrive at a justifiable judgment about the proper course of action; they need to possess moral motives that prioritise the outcome of their moral reflections; and they need to possess character traits that empower them to follow through on their decision and actually perform the action. In some cases, moral agents can also need to possess a certain competence to achieve a morally successful outcome.

Ethical failures - including failures by professionals to live up to their professional duties and ethical codes - can occur through a breakdown in any one of these several processes. Such a failure might be individual in nature, or (as we will see) it might occur because of a lack of social and institutional supports that could have empowered the agent to overcome or bypass their personal deficiency.

This article examines the types of institutions, supports and initiatives that can be employed to target each of the deficiencies that professionals may possess - deficiencies that can prevent their performing their professional duties on the basis of intrinsic respect for those duties. Specifically, the article develops a model of an 'ethics regime', describing the elements that contribute to empowering professionals with the moral motives and capabilities required to act morally. ${ }^{1}$ By 'act morally', I refer (here and throughout) to a professional not

* $\quad$ Research Fellow, Law Futures Centre, Griffith University. (Correspondence: h.breakey@griffith.edu.au). I acknowledge the support of the Australian Research Council and the Professional Standards Councils for this work. I am also grateful for the support of professional partners to the grant, law firms Allens and Corrs. I also acknowledge the support of the Centre for Law Markets and Regulation at UNSW Law for this work.

1 As I define it here, an 'ethics regime' differs from the related notion of an 'integrity system'. An integrity system describes the elements that lead to appropriate moral outcomes (specifically, institutions living up to their publicly stated values). The integrity system focuses on results, not intentions, and while the 
only acting in conformity with moral rules, but of doing so conscientiously out of intrinsic respect for those rules, such that the professional would act in this way even if no-one was watching, and without any thought for potential sanctions for non-compliance.

The article proceeds as follows. Part II overviews the ethics regime model, showing the interrelation of its key elements - including demanders, institutions, initiatives, supports, obstacles, moral motives and moral capabilities. These latter two elements (moral motives and capabilities) are described in some depth, drawing on the influential moral psychological approach trail-blazed by James Rest. At this stage, the two elements are described - following Rest - in individualistic terms. Part III turns the focus to professional ethics, detailing the moral motives and capabilities required for professionals to conscientiously perform their professional obligations. This Part also notes some of the major obstacles that erode each specific capability, or stymie its effect in the given situation. To respond to these obstacles, Part IV turns to the social, institutional and contextual supports that can be employed to cultivate and empower the requisite moral capabilities in professionals.

By the article's close, we will be in a position to revise the earlier, individualistic model of moral action, by showing how interpersonal qualities and environmental supports can impact beneficially on professionals' ethical performance. Having illustrated the major components of a professional-ethics regime, the model can assist reformers in diagnosing the specific types of failures preventing ethical conduct, and developing specific reform initiatives to target those failures.

One of the reasons surgically-targeted reform is important is that - as I argue below - the contents of the vital element of 'moral motives' are not easy to simply produce. One cannot just conjure an ethic into existence. Capabilities, on the other hand, can prove responsive to targeted ethical reforms. Understanding all the elements required by an ethics regime thus allows the most promising and cost-effective reforms to be selected - rather than just the oft-heard generic invocations about the need to change poor organisational culture.

system encourages the conscientious performance of duties, it will employ economic incentives, punitive deterrence, and other governance measures in order to ensure obligations are performed irrespective of the agent's specific intention. In contrast, an 'ethics regime' describes an environment designed to motivate agents to obey the rules for the right reasons - out of an intrinsic respect for the relevant rules and goals (and not for some other reason, such as fear of sanction). Of course, the two systems are complementary, in the sense that both aim to improve moral behaviour and institutional action. On integrity systems, see Figure 1 in Hugh Breakey and Charles Sampford, 'National Exams as a Tool for Improving Standards: Can Australian Financial Advisers Take a Leaf from the Professionals' Book?' (2017) 40 University of New South Wales Law Review 385, 410. See also Noel Preston and Charles Sampford, 'Institutionalising Ethics' in Noel Preston, Charles Sampford and Carmel Connors (eds), Encouraging Ethics and Challenging Corruption: Reforming Governance in Public Institutions (Federation Press, 2002) 32; Hugh Breakey, Tim Cadman and Charles Sampford, 'Conceptualizing Personal and Institutional Integrity: The Comprehensive Integrity Framework' in Michael Schwarts, Howarth Harris and Debra Comer (eds), The Ethical Contribution of Organizations to Society (Research in Ethical Issues in Organizations vol 14, Emerald Group Publishing, 2015) 1. 


\section{OVERVIEW OF THE ETHICS REGIME MODEL}

An influential tradition in moral psychology, building on the seminal work of James Rest, ${ }^{2}$ distinguishes the process giving rise to moral action into several component stages. Each of these stages have their own psychological qualities that empower the moral agent to successfully perform them. In what follows, I will build upon - and adapt to our purposes - Rest's multi-stage procedure (which I will refer to as the 'moral process').

The proposed moral process has six stages. ${ }^{3}$ This Part outlines these stages for a hypothetical moral agent 'Andrew'. (The following Part will detail these stages in the specific context of professional ethics, using 'Patricia' as a hypothetical professional.) For each stage, I name a psychological quality that allows Andrew to successfully navigate that stage. The names I give to these qualities - 'moral sensitivity', 'moral reflectiveness', 'moral motives' and so on - I employ as technical terms defined in terms of their function at each stage in the moral process. That is, 'moral sensitivity' connotes whatever psychological qualities help Andrew become aware of his situation's morally salient features. Similarly, 'moral reflectiveness' connotes whatever psychological qualities help Andrew accurately judge the moral duties the situation requires of him. As we will see below, Andrew may employ a variety of psychological resources to navigate his way stage-by-stage through the moral process. The qualities required to navigate each stage are moral capabilities, in the sense that Andrew can be better or worse at performing each function, and that he can wish he possessed these capabilities, even if he does not. The only exception to this is the third stage, which calls upon Andrew's moral motives, rather than his capabilities. This quality refers to what Andrew wants to do, rather than what he can do.

Stage 1: Awareness. In order to begin the moral process, Andrew must first realise his situation contains morally salient features. Sometimes these features will be obvious - such as Andrew being involved in the direct harm of an innocent person. In other cases, the situation's moral dimensions may be subtler, and a well-honed acuity may be required to excavate them. Andrew's moral sensitivity - including empathy, attention, perceptiveness and curiosity - alerts him to the fact that he is confronted with a moral situation, and helps him

2 See James R Rest, 'A Psychologist Looks at the Teaching of Ethics' (1982) 12(1) The Hastings Center Report 29; James R Rest, 'Morality' in Paul H Mussen (ed), Handbook of Child Psychology (John Wiley \& Sons, $4^{\text {th }}$ ed, 1946) vol 3, 556. On the application of Rest's work to professional ethics, see James R Rest, 'Background: Theory and Research' in James R Rest and Darcia Narváez (eds), Moral Development in the Professions: Psychology and Applied Ethics (Taylor \& Francis, first published 1994, 2009 ed) 1; Neil Hamilton and Verna Monson, 'The Positive Empirical Relationship of Professionalism to Effectiveness in the Practice of Law' (2011) 24 Georgetown Journal of Legal Ethics 137; Neil Hamilton and Verna Monson, 'Legal Education's Ethical Challenge: Empirical Research on How Most Effectively to Foster Each Student's Professional Formation (Professionalism)' (2011) 9 University of St Thomas Law Journal 325. I draw upon various additions and revisions of Rest's work in what follows, especially Linda Klebe Trevino, 'Ethical Decision Making in Organizations: A Person-Situation Interactionist Model' (1986) 11 The Academy of Management Review 601; Mark S Schwartz, 'Ethical Decision-Making Theory: An Integrated Approach' (2016) 139 Journal of Business Ethics 755.

3 Rest's theory encompasses four stages. I split Rest's final stage into the distinct elements of action and achievement, and follow Schwartz in adding a final review stage: Schwartz, above n 2. 
recognise the situation's morally-relevant aspects. If Andrew's moral sensitivity failed to alert him to the moral issues facing him, then he might later explain his failure by saying: 'It didn't even occur to me that there might be a problem here'.

Stage 2: Judgment. Andrew needs to move from apprehending his situation's morally-relevant features to a correct judgment about what morality requires of him. Making this judgment requires moral reflectiveness - an array of psychological qualities that serve to lead Andrew to a justified judgment of morality's requirements. These qualities can include conscious, deliberate and highly rational reasoning capabilities. But they may also include more intuitional, emotional, habitual and instinctive modes of thought. ${ }^{4}$ If Andrew's moral reflectiveness failed to lead him to a correct judgment, then he could later explain that failure by saying: 'I made a mistake; it was a serious error of judgment'.

Stage 3: Decision-making. Having arrived at a correct judgment about morality's demands, Andrew must then possess the moral motives that impel him to prioritise those demands and choose to act on their basis, even in the face of potentially powerful countervailing desires, such as self-interest or groupinterest. ${ }^{5}$ If Andrew's moral motives fail to impel him to act upon his considered moral judgment, then he could explain that failure by saying: 'I knew it was wrong. I just didn't care enough to act on that judgment'.

Stage 4: Action. Having decided he wants to act morally, Andrew must now follow through on his decision. While in some cases action may be straightforward, in other cases it may call for a test of the strength of his moral character. 'Moral character' covers the types of personality traits that empower Andrew to translate his decisions into action. These traits can be thought of as virtues: stable personality attributes that shape when and how the agent feels emotions, and how the agent responds to those emotions. These virtues include staples such as courage, patience, concentration, perseverance and kindness, and

4 On the importance of intuitive rather than reason-based processes in the judgment stage, see Schwartz, above n 2, 758 and more generally Jonathan Haidt, The Righteous Mind: Why Good People are Divided by Politics and Religion (Penguin, 2012).

5 Like the other terms for each stage, 'moral motive' is a term of art, defined functionally as whatever psychological qualities motivate the agent (Andrew) to accord respect to his moral judgment and so decide to act upon it. Because of this functional definition, 'moral motives' resist classification into any neat psychological category. At a minimum, each moral motive will necessarily include an array of values, in the sense defined by Milton Rokeach. For Rokeach, a value is an enduring, singular prescriptive belief about the personal or social desirability of an act or goal, serving as an imperative for action. Rokeach's values are always 'centrally connected' to the subject's overall belief system, meaning they are functionally and cognitively linked to many other beliefs and attitudes. See Milton Rokeach, Beliefs, Attitudes and Values: A Theory of Organization and Change (Jossey-Bass Publishers, 1968), 123-4, 159-60. While moral motives will always include such values, they also possess a more elaborate nature (as the examples in Part III(C) illustrate), including other belief structures, like attitudes, ideologies and philosophies of life. Particular moral motives may also include further psychological attributes, such as perceptual capacities, cognitive habits, affective responses and personality traits - in short, any psychological processes that can work alongside values to impel conscientious moral action. For discussion of several of these psychological attributes, see Rokeach at 111, 123-5, 131. See also Hugh Breakey, 'Same Duties, Different Motives: Ethical Theory and the Phenomenon of Moral Motive Pluralism' (2017) Philosophical Studies forthcoming <http://link.springer.com/article/10.1007/s11098017-0881-x>. 
broader character attributes such as emotional intelligence. ${ }^{6}$ If Andrew's moral character fails to support him in acting morally, then he could explain that failure by saying: 'I wanted to do the right thing, but when push came to shove, I just wasn't able to follow through'.

Stage 5: Achievement. Often, performing the required moral action, and striving to do so as well as possible in the face of challenges, is all that morality can demand of anyone. However, in some cases, Andrew also may be judged on the basis of his moral competence - understood in this context as his capability to successfully implement his moral decisions and to achieve morally important goals. For example, if Andrew chooses to display respect to others, but he fails in his words and actions to display such respect (perhaps because of his lack of experience in, and attention to, relevant social rituals), then others may morally judge him on that failure. The capabilities that fall under the banner of moral competence will vary depending on context, but may include interpersonal experience, specialised expertise, strategic nous, and social skills (like leadership, charm, diplomacy, and conflict-resolution skills). If Andrew's moral competence sees him fail in his attempts to secure some morally important goal, then he could later explain that failure by saying: 'I gave it my best, but in the end, I just wasn't able to perform at the required level'.

Stage 6: Review. 'Review' refers to Andrew's later evaluation of his action, as he reflects on his decision and its results. This sixth stage is not strictly speaking necessary to moral action (or even to successful moral action). However, review still warrants inclusion in the moral process for several reasons. Most importantly, a re-evaluation may occur in time for Andrew to alter the action (for example, if its institutional implementation had not yet been completed). Andrew also might be able to mitigate some of his action's consequences that (upon reflection) appear worrying. And Andrew may revisit the action by apologising, admitting error and offering recompense. Even if it is too late for such actions, important learning can follow from the review stage. This learning can then impact upon Andrew's behaviour in future cases, perhaps providing him with an improved judgment, or prompting him to put in place resources that expand his feasible options.

Figure 1 graphically illustrates the six stages of the moral process, and the qualities of moral capabilities and moral motives required to navigate each stage. The downward arrow on the right hand side indicates the direction in which the qualities typically will be exercised. Figure 1 portrays the moral process in individualistic terms regarding personal qualities. Later, we will be in a position to incorporate interpersonal qualities and institutional supports.

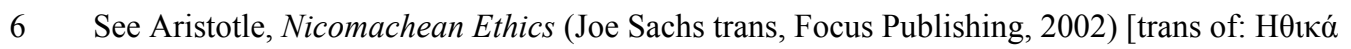

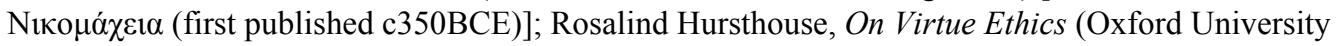
Press, 1999); Confucius, The Analects (D C Lau trans, Penguin, 1979). On the links with emotional intelligence, see, eg, John E Montgomery, 'Incorporating Emotional Intelligence Concepts into Legal Education: Strengthening the Professionalism of Law Students' (2008) 39 University of Toledo Law Review 323. 


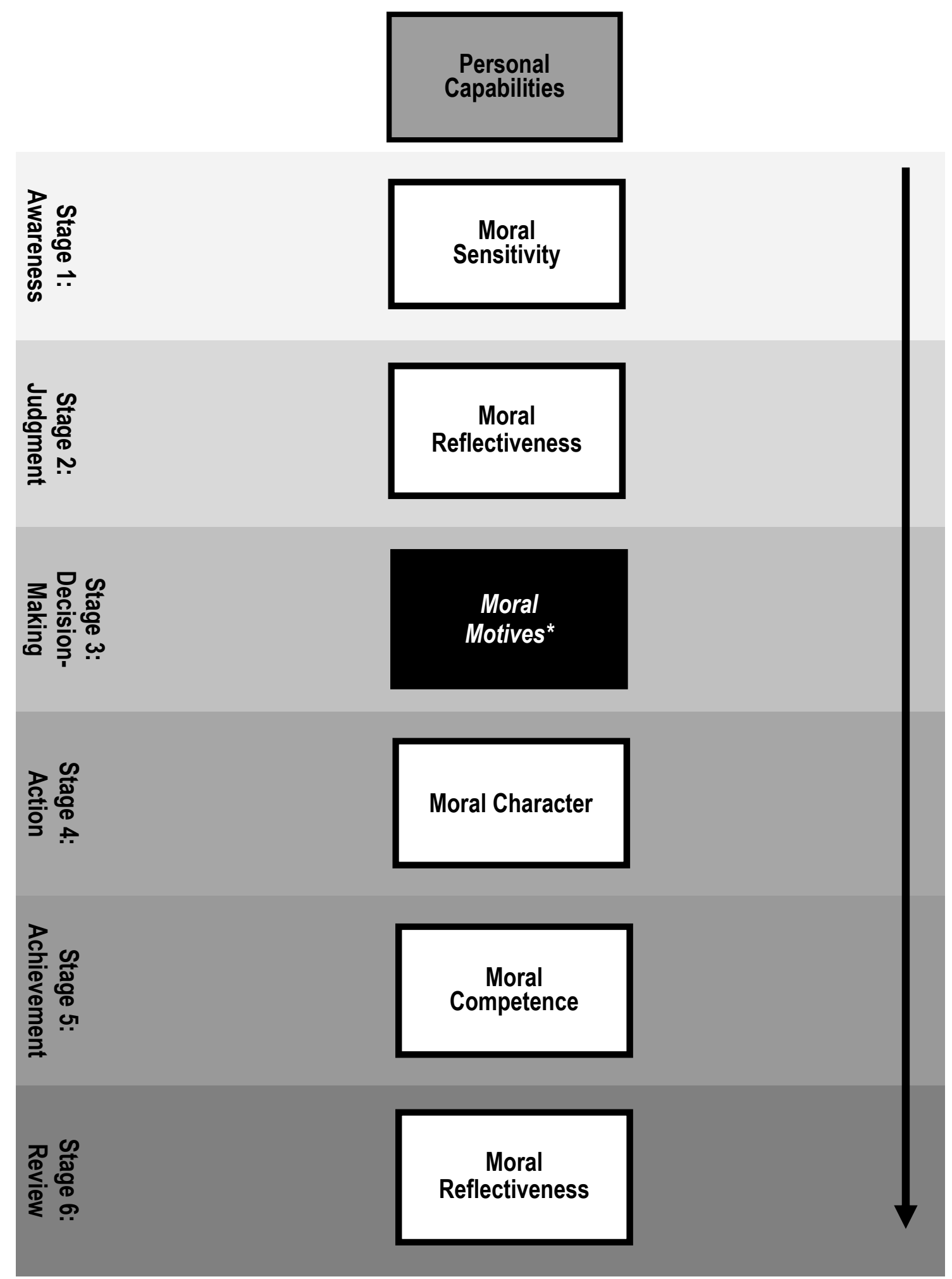

${ }^{*}$ Moral Motives are values, not capabilities.

Figure 1: Flow-chart of stages and personal qualities in the moral process

With the moral process set down, we now turn to the components of the ethics regime. Figure 2 provides a graphic overview of the regime. The moral 
process we have been discussing sits at the bottom of Figure 2, where the moral motives and the (four) moral capabilities combine with a feasible option to deliver a successful moral outcome. The aim of the ethics regime is to support the moral agent in possessing those moral motives, moral capabilities and feasible options.

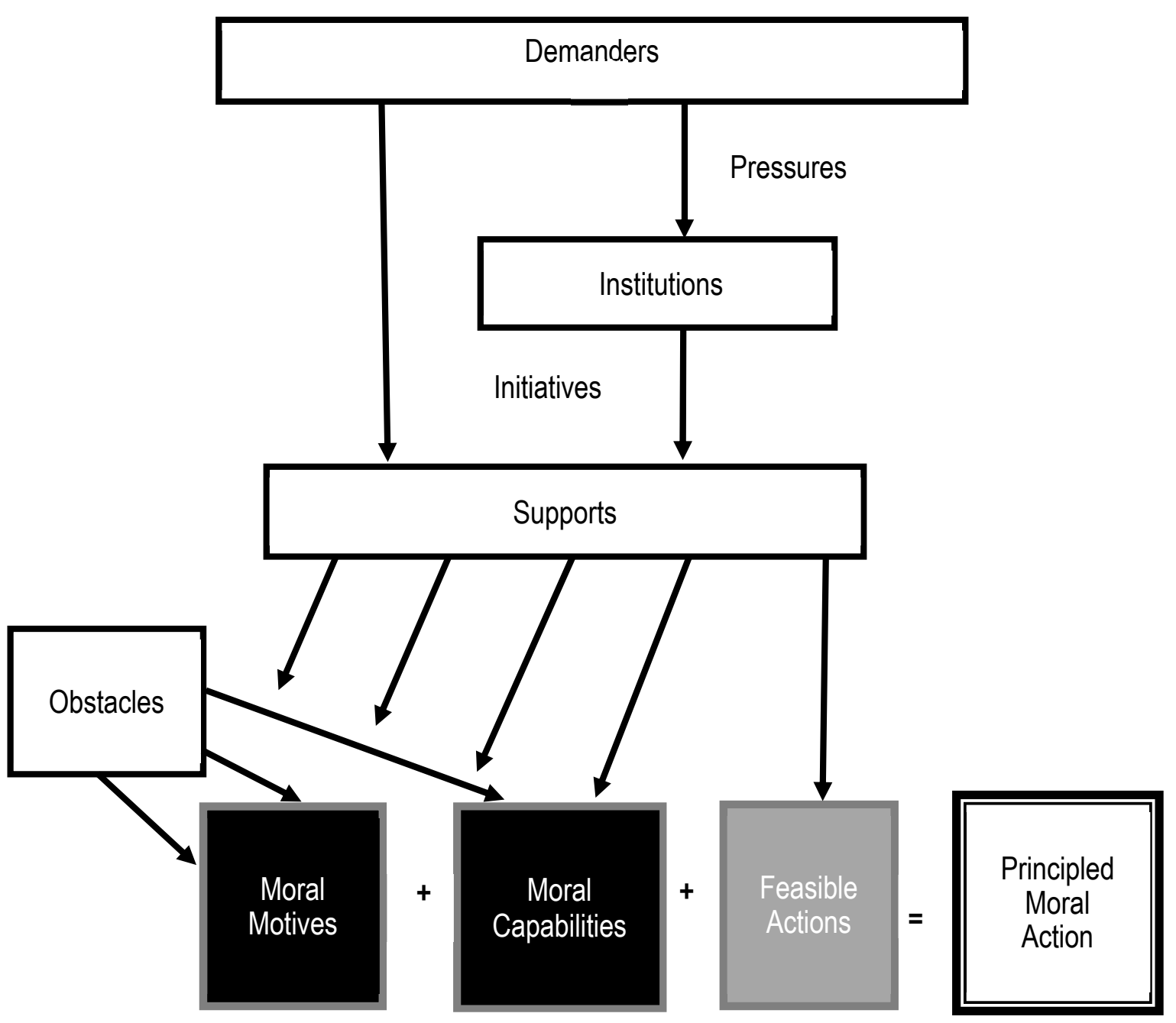

Figure 2: Key Components of an Ethics Regime

To this end, demanders (at the top of Figure 2) exert pressure in a variety of modes, calling for the creation, reform or preservation of a moral norm or set of norms. ${ }^{7}$ In the context of professional ethics, demanders include clients and

7 This ethics regime model builds on prior work that explains two of the model's key elements ('demanders' and 'moral motives') in more detail. See Hugh Breakey, 'Supply and Demand in the Development of Professional Ethics' in Marco Grix and Tim Dare (eds), Contemporary Issues in Applied and Professional Ethics (Research in Ethical Issues in Organizations vol 15, Emerald Group Publishing, 2016) 1. (I employ slightly different terminology in that work, referring to 'moral motives' as the 'ethical materiel' that provides 'supply' in answer to the demanders' demands). This prior work built upon other like-minded approaches: see, eg, Deen Sanders, Professional Enlightenment of Financial Planning in Australia (PhD Thesis, Central Queensland University, 2010) <http://hdl.cqu.edu.au/10018/918259>; Deen Sanders and Alex Roberts, 'Professionalisation of Financial Services' (White Paper, Professional 
prospective clients, and third-party stakeholders across the wider society. Professionals, themselves, represent a special case of demanders: such groups can possess strong reasons to wish for the collective gains that derive from a powerful, es tablished in-group norm. But having good reason to want a norm to exist does not thereby wish it into existence.

Sometimes, the demanders' pressure can directly support the professional ethic. More often, the pressure will be mediated through institutions. In turn, these institutions can produce supports, which are processes or instruments that enhance the professionals' moral motives or their capabilities to convert those motives into effective action.

One important role of the supports is to stymie the presence and effect of obstacles. Obstacles press against the professional's performance of their moral duties by eroding or impeding their moral motives or capabilities.

In the ideal case, pressure from demanders succeeds in building institutions and developing initiatives that support agents' moral motives and capabilities. Combined with a feasible and available option, the ethics regime delivers its desired result: successful moral behaviour, conscientiously performed.

\section{MORAL MOTIVES, CAPABILITIES AND OBSTACLES FOR PROFESSIONAL ETHICS}

This Part explains the moral qualities as they apply in the context of professional ethics, and notes various obstacles that tend to undermine or subvert their operation in that context. We now turn from speaking of our generic moral agent, 'Andrew', to our hypothetical professional: 'Patricia'.

\section{A Moral Sensitivity}

In professional contexts, we can distinguish two types of moral sensitivity required to successfully navigate the first stage of the moral process. The first is the general awareness that a certain class of situation has morally-concerning features. For example, Patricia may learn that being in a certain type of situation counts as her possessing a conflict of interest. Such general awareness might derive from Patricia's prior moral reflections, where she reasoned from general principles to specific situations. Alternatively, Patricia's general awareness can include knowledge derived from direct instruction, formal education, supervised work (internships and apprenticeships), codes of ethics and personal experience. ${ }^{8}$

Standards Councils, January 2015). On several of the key assumptions this approach requires, see Breakey, 'Supply and Demand', above n 7, 2-4.

8 Because general awareness can be learned in other ways than one's own moral reflectiveness, it cannot be fully reduced to the second capability of moral reflectiveness. This is particularly so for professional ethics, which involve established codes and social arrangements that collectively create social goods. Reasoning alone, without awareness of these contingent features of the social topography, cannot deliver a full explication of the compass of professional duties: see Kenneth Kipnis, 'Ethics and the Professional Responsibility of Lawyers' (1991) 10 Journal of Business Ethics 569. 
The second type of sensitivity required is the specific awareness that occurs when Patricia recognises that her current situation possesses morally relevant features. Specific awareness for Patricia will require various character traits and habits of mind, including alertness, perceptiveness, curiosity, listening skills, interview skills, empathy, sympathy and experience.

\section{Obstacles to Professionals' Moral Sensitivity}

In professional work, moral sensitivity may be blocked in several ways. I note two key obstacles.

Perhaps the most direct obstacle to professional sensitivity lies in the use of 'scripts'. Scripts are cognitive processes that map existing knowledge onto a template for understanding and response. As such, scripts provide vital occupational tools in being able to respond to information-rich situations in an effective and timely fashion. ${ }^{9}$ Scripts can, themselves, incorporate moral concerns, such as by establishing a routine mode-of-business whereby professionals inform clients (and patients) of the options before them, and their potential benefits and risks. By following this script, and directing their attention and concern in line with its demands, professionals respond to the moral principle of respecting clients' autonomy and their capacity to make informed decisions. ${ }^{10}$

Equally however, scripts that do not include a concern for (perhaps unusual) ethically-relevant factors can foment moral blindness, as the agent follows the script even in the face of moral factors that would otherwise seize their attention. The most famous case of this ethical blindness was that self-diagnosed by Dennis Gioia in the wake of his involvement in the Ford Pinto case. ${ }^{11}$ Ford's prevailing (cost-benefit-analysis) scripts failed to focus decision-makers' attention on ethically charged features of its Pinto's performance - namely the small car's fatal capacity to erupt into an all-consuming fire when impacted from the rear. The problem in this case was not caused by a failure of Gioia's moral motives, but that his role-based need to follow scripts in order to render his job manageable impeded the capacity for his moral motives to inject themselves into his decision-making.

Another type of obstacle for sensitivity is 'compassion fatigue' (also known as 'empathic distress' or 'burnout'). Professionals - especially doctors, nurses and lawyers - routinely deal with distressing situations and can be bearers of lifeshattering news. The operation of normal empathy in such situations can

9 Time pressures can themselves degrade awareness, as demanding tasks leave less cognitive space for noticing impacts on others: Trevino, above $\mathrm{n} 2,614$.

10 On the positive significance of scripts to moral action, see, eg, Chris Provis, 'Confucianism, Virtue, and Wisdom’ in Alejo José G Sison, Gregory R Beabout and Ignaccio Ferrero (eds), Handbook of Virtue Ethics in Business and Management (Springer, 2015) 425.

11 Dennis A Gioia, 'Pinto Fires and Personal Ethics: A Script Analysis of Missed Opportunities' (1992) 11 Journal of Business Ethics 379. 
ultimately prove emotionally and even physically debilitating, ushering in a shutdown of this vital emotion for moral sensitivity. ${ }^{12}$

\section{B Moral Reflectiveness}

After Patricia becomes aware of a situation's morally relevant features, she needs to think her way through to a correct understanding of morality's requirements. Because our focus here is on improving the conscientious performance of professional duties, we can stipulate that this 'correct understanding' refers to Patricia arriving at a judgment that accords with the spirit and letter of her profession's codes, in both their aspirational and regulative modes. ${ }^{13}$

For the professional, this broad capability can include an array of cognitive capabilities, including:

- clear critical thinking, allowing the professional to form an accurate picture of the situation from the available evidence;

- the capacity to understand underlying moral principles and the way they provide reasons for, and give purpose to, specific rules and institutions;

- the ability to apply established professional rules correctly to particular cases, and to know when exceptions to those rules are appropriate;

- the capacity to rationally analogise from known situations with established norms to relevantly-similar situations;

- the capacity to 'think like' a professional, by understanding the specific roles of the professional, and how they are expected to weigh different priorities; ${ }^{14}$

- intuitions, emotional responses, cognitive heuristics, and the results of previous trial-and-error learning. ${ }^{15}$

One final capability forms an important ingredient of a professional's moral reflectiveness: namely, the capacity to uncover the various alternative courses of action open to the decision-maker. ${ }^{16}$ This capacity calls upon the professional's

12 Hamilton and Monson, 'The Positive Empirical Relationship', above n 2, 146; Colin James, 'Seeing Things as We Are: Emotional Intelligence and Clinical Legal Education' (2005) 8 International Journal of Clinical Legal Education 123. See also Cécile Rozuel, 'The Moral Threat of Compartmentalization: Self, Roles and Responsibility’ (2011) 102 Journal of Business Ethics 685, 694-6.

13 Professional codes are thus used to 'set' what counts for our purposes as correct and effective ethical action and, therefore, what moral sensitivity, reflectiveness, motives, character, and competence should aim at achieving. (Well-written and widely promulgated professional codes - the texts themselves - are also one element of an ethics regime, potentially aiding awareness and reflectiveness. However, unless consistent with organisational culture, and well-enforced, the literature suggests codes on their own can be ineffective: Trevino, above n 2,613).

14 See Michael Davis, 'Thinking Like an Engineer: The Place of a Code of Ethics in the Practice of a Profession' (1991) 20 Philosophy \& Public Affairs 150.

15 On the importance of these non-reasoning attributes to moral decision-making, see generally Haidt, above n 4.

16 This capability lies implicit in Rest's formulation of how ethical decision-making occurs, inasmuch as it stands as one of the cognitive capacities required to render up a justifiable verdict on the correct course of moral action. But the capability itself is not one Rest attends to in any detail. 
expertise, intelligence, experience, strategic reasoning and problem-solving capabilities - and even their originality, imagination and lateral thinking - to unearth a wide suite of feasible moral options.

\section{Obstacles to Professional Moral Reflectiveness}

Obstacles to Patricia's moral reflectiveness include factors like 'cognitive distortions', where she proves unrealistically optimistic about outcomes or possesses unrealistic beliefs about her professional omniscience or omnipotence (and so over-estimates her expert knowledge, or her power to control a situation). ${ }^{17}$ Conversely, under-confidence in any of these estimations may also lead Patricia to poor decision-making: without self-belief, and a reasonable faith in other people and institutions, a misplaced sense of futility might distort her moral reflections.

Another potential obstacle occurs if Patricia distorts or even replaces her moral judgment processes with other types of normative thinking. ${ }^{18}$ One concern here might be the use of political ideologies whose moral motives are inimical to those set down in the professional code. ${ }^{19}$ Equally, a misplaced sense of loyalty to her employer or organisation might deleteriously infect Patricia's decisionmaking. So too, an earlier mistake of moral reflectiveness - such as one that delivered a misplaced sense of entitlement - may set the stage for a later collapse in Patricia's moral judgment - such as when the misplaced expectation is subsequently disappointed..$^{20}$

A final distortion in reasoning can occur through the self-serving use of excuses. One of the abiding insights of the $18^{\text {th }}$ century enlightenment philosopher Immanuel Kant, was the worrying capacity of human agents' moral reflectiveness to confect specious rationalisations that exempt themselves from the operation of a general rule..$^{21}$ Recent criminological work aligns with Kant's concern: criminals routinely appeal to considerations that, while they well may be legitimate excuses in other contexts, are applied in a self-serving way so as to excuse (what an external observer would immediately recognise as) patent wrongdoing. Heath notes an array of these 'neutralizing excuses', including methods of denying one's responsibility ('I was provoked.'), denying the

17 Hamilton and Monson, 'The Positive Empirical Relationship', above n 2, 180.

18 Rest posits the worry that 'a subject may simultaneously (or as a substitute) be figuring out what course of action optimises other nonmoral ideals as well (eg, religious ideals)': Rest, 'Morality', above n 2, 561. I follow Rest in including this as a potential problem for reasoning, though it also may be noted as a problem for values.

19 Neo-liberal doctrines provide a plausible example, as do various forms of postmodernism. See the discussion of Friedman's view of corporate responsibility in Hugh Breakey and Charles Sampford, 'Employed Professionals' Ethical Responsibilities in Public Service and Private Enterprise: Dilemma, Priority and Synthesis' (2017) 40 University of New South Wales Law Journal 262, Part VII(C). See also Kevin T Leicht, 'Market Fundamentalism, Cultural Fragmentation, Post-modern Skepticism, and the Future of Professional Work' (2016) 3 Journal of Professions and Organization 103.

20 On losses in the context of misplaced sense of entitlement, see Joseph Heath, 'Business Ethics and Moral Motivation: A Criminological Perspective' (2008) 83 Journal of Business Ethics 595, 600.

21 Immanuel Kant, The Moral Law: Kant's Groundwork of the Metaphysic of Morals (H J Paton trans, Hutchinson's University Library, 1948) [trans of: Grundlegung zur Metaphysik der Sitten (first published 1785)]. 
victim's status ('They deserved it.'), denying the injury caused ('They consented to it.'), and many more. ${ }^{22}$

\section{Moral Motives}

Whether Patricia will act upon her considered judgment depends on her moral motives. Theories of professional ethics can help distil the different forms these moral motives may take. Our focus here is not on the philosophical question of which of these theories is right - that is, which one ultimately succeeds in justifying professional ethics. Instead, our interest is in feltmotivation. ${ }^{23}$ The question is: does the theory put forward a plausible set of reasons why (some) professionals might grant professional codes intrinsic respect, and therefore prioritise the performance of their professional duties ${ }^{24}$

Here, I summarise six broad types of motive ${ }^{25}$ that, the literature suggests, can impel professionals like Patricia to grant intrinsic respect to their professional duties. ${ }^{26}$ These moral motives include:

1. Common morality: Many professional obligations follow from everyday moral duties, such as to help and respect others, and to be honest and trustworthy. In such cases, Patricia will be motivated by the same sources that drive her ordinary moral compliance. ${ }^{27}$

2. Desirable role-identity: Professionals' roles can be valorised through tradition, and by historical and fictional stories, associating them with notions of status, dignity and honour. These notions can encourage Patricia to identify with her role and feel personally invested in it,

22 Heath, above n 20, 602-4.

23 On this distinction between justification and motivation in the context of business and professional ethics, see Tetsuji Iseda, 'How Should We Foster the Professional Integrity of Engineers in Japan? A PrideBased Approach' (2008) 14 Science and Engineering Ethics 165, 166; Trevino, above n 2, 604.

24 Professionals' convictions about high philosophical theories - such as deontology, utilitarianism and virtue theory - might play a deeper, foundational role in each of these moral motives. However, the abstractness of such theories calls for caution in assuming their relevance to felt-motivation: see Trevino, above n 2, 604; Haidt, above n 4, 149. In contrast to foundational ethical theories, the six moral motives presented here operate at a lower level of abstraction, and invoke commonsense and widespread motives for action (excellence, admirableness, reputation, etc). For these reasons, they present plausible candidates for professionals' actual felt-motivations.

25 For more detail, see Breakey, 'Supply and Demand', above n 7, 11-21. The six motives are illustrative, not exhaustive.

26 These six moral motives correlate with the different modes of moral reflectiveness noted above. Certain types of moral motives - such as excellence or honour - will encourage more intuitive (rather than rational) modes of reflection.

27 Of course, it is a much disputed philosophical-cum-psychological-cum-sociological question what the exact operative motivation for everyday morality is. For some major contributions, see Thomas Hobbes, Leviathan (Oxford University Press, first published 1651, 2008 ed); David Hume, A Treatise of Human Nature (Penguin Books, first published 1739, 1969 ed); Kant, above n 21; John C Gibbs, Moral Development and Reality: Beyond the Theories of Kohlberg and Hoffman (Penguin Books, $2^{\text {nd }}$ ed, 2010); Rest, 'Morality', above n 2. See also Breakey, 'Same Duties Different Motives', above n 5. For our purposes, we can simply note that whatever motives drive commonsense moral action, such intentions can be directed to drive professional ethics in cases where the common morality straightforwardly justifies the professional obligation. 
motivating her compliance with the morality that is partly constitutive of that role.

3. Excellence: Professional codes put forward distinct 'constitutive' activities, describing the professionals' signature tasks. These constitutive activities require judgment and expertise to be performed successfully. The collective practice of performing such tasks gives rise to standards of excellence. In aspiring to such heights, Patricia obeys the ethical constraints that make her pursuit of excellence within the profession possible.

4. Covenants and fair bargains: In cases where professionals enjoy high social status, special legal privileges, regulatory autonomy or elevated financial remuneration, professionals can be motivated to live up to their end of the bargain that delivers them these goods. This implicit (and sometimes explicit) quasi-contractual obligation can be understood as being owed to clients, to the general community, or to one's fellow professionals.

5. Constructed virtues: Inculcation in the professional environment can engrain certain types of emotional responses and habits of mind. This manifestation is especially visible in team-contexts that create habituated responses that meet with peers' approval and understanding. As an aspiring professional, Patricia began to learn how to 'think like' a doctor (or nurse, engineer, etc), and part of this 'thinking like' directed her emotional responses and habits of mind in line with her professional duties.

6. Deserved approbation: While the desire for social and peer approbation is not itself a moral motive, ${ }^{28}$ the yearning for deserved social admiration - that is, approbation for genuine ethical achievements - can provide a powerful motive for moral action. Patricia's yearning for public and peer appreciation for her impressive deeds can drive her towards exemplary moral performance.

\section{Obstacles to Professionals' Moral Motives}

These six types of moral motives can be eroded or overwhelmed in myriad ways. We noted above how various types of exceptionalism, including misplaced loyalties, may intrude on the reasoning process. Equally, Patricia's egoistic or even narcissistic desires, as well as more her more ordinary loyalties and partialities, may overwhelm the stirrings of her moral conscience. ${ }^{29}$

As a professional, Patricia may be exposed to subtle forms of value erosion. For example, David Luban highlights concerns with lawyers' professional obligations to advocate for their clients. ${ }^{30} \mathrm{He}$ shows how the operation of

28 The desire for esteem does not create intrinsic respect for a rule, and so does not count as a moral motive for our purposes.

29 Hamilton and Monson, 'The Positive Empirical Relationship', above n 2, 180.

30 David Luban, 'Integrity: Its Causes and Cures' (2003) 72 Fordham Law Review 279. 
standard psychological processes, such as cognitive dissonance, can prompt the lawyer to acquire an inflated sense of the righteousness of the client's position even to the point where the lawyer betrays other professional duties to serve the client.

\section{Moral Character}

Once the professional has decided to perform the moral act, it is still an open question whether that act actually will be performed - especially if it must be performed in a hostile situation. For Patricia, moral character will include any role-based cognitive/emotional traits specific to her particular profession. These traits may include the cognitive habits involved in 'thinking like' an engineer or accountant, or the emotional predispositions that modulate Patricia's emotional responses in professional contexts. An example of the latter would be the 'detached concern' that doctors and nurses can employ when relating bad news. Such professionals need to be concerned in the sense of acknowledging the gravity of the situation and the need to emotionally support the patient - but at the same time they must be detached so that they are not so overwhelmed that they become incapable of dealing appropriately with the situation's professional demands.

\section{Obstacles to Professionals' Moral Character}

In a sense, there should be no 'obstacles' to professional character. If a professional's character is strong enough, then she will be able to overcome any obstacles confronting her. That, after all, is what character is for.

Even so, it is worth noting perennial psychological factors, like conformity and deference to authority, which often serve to undermine the effective functioning of a persons' character. ${ }^{31}$ Even if Patricia is normally compassionate enough to resist performing obvious moral wrongs, the pressures created by peergroups and authority-figures may pose powerful obstacles to the activation of her compassion.

\section{E Moral Competence}

Moral competence becomes singularly important in the context of professionalism. While laypeople like Andrew can sometimes be morally blameworthy if they fail to successfully execute their moral actions, professionals like Patricia present themselves as holding standards of competence and expertise. Professional standards call for the delivery of expert judgment. Without the expertise drawn from her tertiary education, her practical experience, and her ongoing life-long learning, Patricia will be unable to live up to the performance standards demanded by her ethics.

As well as expertise in the knowledge domain of her professional area, Patricia's moral competence will include key interpersonal and communicative

31 Such lessons follow from influential work in social psychology, including the Milgram Experiment on the willingness to inflict pain, and the Stanford Prison Experiment on roles and authority. See Trevino, above n 2,612 . 
skills, including listening and questioning (interview) skills, giving constructive criticism, strategies for broaching ethical issues, experience in evaluating strategic options in different social contexts, and leadership qualities. Without a sufficient portfolio of such traits, Patricia's moral actions may fail to secure their required objectives, and - given the irreversible nature of professional (eg, legal, financial and medical) action - may even make things worse.

Finally, professional activities are increasingly performed in team environments, with various responsibilities disaggregated through a larger institutional complex (such as a hospital or corporatised law firm). In such cases, in order for a client to receive appropriate care and treatment, the system (or team) as a whole will need its members to succeed in playing their part in the larger process - and in coordinating and communicating as they do so.

\section{Problems and Blocking Factors: Professionals' Moral Competence}

Like character, competence is a quality that empowers Patricia to overcome obstacles. Even so, social and interpersonal qualities do have limits. In particular, if Patricia is placed in an unfamiliar situation, with new norms, practices, technologies and lines of authority and information-gathering, then her previous strategies may no longer prove effective. (This situation can be a significant problem, for example, for health professionals migrating from developing countries to developed countries.) In such cases, Patricia may need to gather substantial experience before she is able to pursue her moral goals effectively.

\section{F Moral Reflectiveness (Review Stage)}

Moral reflectiveness appears at two stages in the moral process - in the formation of judgment, and also later if Patricia reviews her action. One of the review stage's key advantages is that Patricia's reflections can proceed without suffering from the limitations and pressures (such as time constraints, or being thrown into an unfamiliar context) that constrained her earlier decision-making. Outside the immediate situation, Patricia may be able to bring a different perspective to bear as she evaluates her actions and their outcomes.

\section{Problems and Blocking Factors: Professionals' Moral Reflectiveness (Review)}

Patricia's capacity to engage in reflective review may be thwarted by several obstacles. In particular, if her work requires long hours, and leaves her mentally exhausted (which can occur with early-career professionals), then she may not have the emotional and cognitive space required to devote to serious review of her actions.

A more serious danger is that Patricia's workplace may be populated with colleagues willing to make excuses and exceptions for poor moral compliance. In 
this case, Patricia's review stage may actually degrade her future moral action, as she learns to rationalise her moral failures. ${ }^{32}$

\section{G Generic Obstacles}

Generic obstacles can impact on many professional moral qualities. Wellknown examples include factors like high levels of stress or substance-abuse (alcoholism, drug-dependency). ${ }^{33}$ These factors can create a narrow tunnel vision that inhibits moral sensitivity, impairs reasoning processes, and distorts the professional's moral motives and character by heightening the perceived urgency of non-moral factors.

Factors in the work environment can also pose generic obstacles, such as severe time-constraints that limit Patricia's capacity to stop, reflect, reason, discuss and consider a morally appropriate strategy, especially in unfamiliar situations. ${ }^{34}$ The work environment may also diffuse moral responsibility. In the standard professional-client interaction, the lines of communication, authority and responsibility are clearly established. But in large organisations (such as banks or hospitals), the level of client-interaction, and the responsibility for different aspects of the client's wellbeing, may be smeared across multiple employees. This situation can impact on Patricia's sensitivity and awareness (as key issues might not be properly communicated to all parties); her judgment (as different parties may reason differently about the distribution of responsibilities) and her moral motives (as the personal face-to-face interaction with her client can help trigger empathy and other pro-social emotional responses).

Another generic obstacle created by work environments is 'compartmentalisation'. Compartmentalisation is a broad category covering several ways that our professional, Patricia, may have failed to integrate her rolebased ethic with her larger moral belief-system. ${ }^{35}$ It may refer to a failure of sensitivity whereby Patricia fails to connect her ordinary everyday moral motives to her institutional role because she is insufficiently attentive to the role's moral implications. Alternatively, the failure may be in her reflectiveness, where Patricia confects specious rationalisations - 'it's just business, nothing personal' - to deflect the operation of her everyday moral motives. Or the compartmentalisation may stymie her capacity for review; Patricia may avoid thinking about her work outside of work hours, or considering her professional actions from the perspective of her other social roles (as a family-member, parent, citizen, etc). ${ }^{36}$ All these types of compartmentalisation can be inculcated by institutional circumstances, such as skewed performance metrics, devastating

32 Post hoc rationalisation poses a serious danger in the Review Stage: see Schwartz, above n 2, 769; Haidt, above $\mathrm{n} 4$.

33 Marjorie A Silver, 'Emotional Intelligence and Legal Education' (1999) 5 Psychology, Public Policy, and Law 1173. Other addictions, such as gambling addictions, may drive similar problems.

34 Gioia, above n 11.

35 Breakey, Cadman and Sampford, above n 1, 15-18.

36 Ibid 15-20. 
resource and time constraints, continued opportunities for undetectable low-grade ethical breaches, and more. ${ }^{37}$

\section{Blockers}

As well as obstacles comprising stable features of the socio-economic environment, there are also (what we might term) 'blockers'. Blockers consist of individuals and groups who deliberately intend to disrupt nascent or existing ethical standards. Such blockers can include product-manufacturers (who may want to sell their products directly to consumers, rather than through a mediating layer of professionals) and also lesser-quality service providers, who may be cut out of the market by the growth of a professional organisation with strict standards of quality and ethics. Such blockers must be approached differently to other obstacles, as they can work dynamically and strategically to stymie the growth of professional standards and the organisations that uphold those standards. ${ }^{38}$

\section{H Ambivalent Obstacles and Supports}

Some large-scale contextual factors can, in different conditions, work as generic blockers or as generic supports for moral action.

\section{Market Forces}

The existing market environment, and its attendant pressures and opportunities, presents perhaps the most important example of this category. On the positive side, the market may work as a helpful fillip to the operation of moral sensitivity in cases where clients are able to vote with their feet and their wallets - either by casting off unethical professionals and flooding towards those with better standards, or by shunning an entire occupation of service-providers and seeking assistance from a cognate sector (such as clients using accountants and estate-planners instead of financial advisers). ${ }^{39}$ In these ways, the market's decentralised powers may lend strength to demanders' calls for greater standards.

In addition, the general level of prosperity, security of employment and career trajectory the market environment can supply to professionals may

37 See Breakey, Cadman and Sampford, above n 1, 19, citing Brighid Kelly, 'Preserving Moral Integrity: A Follow-up Study with New Graduate Nurses' (1998) 28 Journal of Advanced Nursing 1134; Gioia, above n 11; Alasdair MacIntyre, 'Social Structures and Their Threats to Moral Agency' (1999) 74 Philosophy 311; Hugh Breakey, 'Wired to Fail: Virtue and Dysfunction in Baltimore's Narrative' in Michael Schwartz and Howard Harris (eds), The Contribution of Fiction to Organizational Ethics (Research in Ethical Issues in Organizations vol 11, Emerald Group Publishing, 2014) 51; Luban, above n 30.

38 In technical terms, blockers are 'non-parametric agents', capable of responding strategically to demanders' efforts and initiatives. Large-scale parametric factors, such as market pressures, may be harder for demanders to overcome, but such factors do not deliberately alter their behaviour to undermine reform initiatives.

39 These behaviours require - to some extent at least - clients and prospective clients being able to accurately gauge the standards of different service-providers. Since professions often provide what Davis terms 'invisible quality', this assessment can pose a challenge. See Michael Davis, 'Professionalism Means Putting Your Profession First' (1988) 2 Georgetown Journal of Legal Ethics 341, 353-5; Breakey, 'Supply and Demand', above n 7, 8-9. 
contribute to the development of moral motives ${ }^{40}$ For example, the assurance of long-term material wellbeing can assist the growth of professional dignity and honour (Desirable Role-Identity), or cultivate high professional social status (facilitating Covenant and Deserved Approbation).

Market forces, however, might press in the opposite direction. Competition may drive a race to the bottom in professional standards, as the least ethical professionals sell out to the highest bidder. ${ }^{41}$ This situation can force professionals to make a hard choice between ethical conduct and economic failure - with all the latter's attendant implications for one's personal and familial wellbeing. Equally, elevated remuneration may replace previous emblems of professional status and honour with the material goods and social attention that money can purchase. ${ }^{42}$

\section{Links between Capabilities and Moral Motives}

While the capabilities of moral sensitivity, reflectiveness, character and competence are vital resources for delivering moral outcomes, moral motives remain of pivotal importance.

For one thing, the nature of the moral motives will shape the nature of the other required qualities. For example, suppose Patricia's main moral motive driving her professional ethical behaviour is the pursuit of excellence. Patricia's desire to excel - and to find opportunities for her to excel - will colour her qualities of moral sensitivity, reflectiveness, character and competence in particular ways. These qualities will have a different flavour, as compared with another professional who focuses on, say, covenants and fair bargains.

Moreover, in the long term, all the other capabilities depend on moral motives. If Patricia possesses strong moral motives, she will be motivated to pursue personal and environmental reforms that will increase her moral achievements in the future. Her moral motives make Patricia want to be capable of moral sensitivity, reasoning, character and competence. Indeed, the presence of moral motives can turn professionals like Patricia into demanders, opening the possibility of their linking together with other demanders, amplifying their voices and concerns, and building institutions to address structural obstacles and wellresourced blockers.

On the other hand, without her personal commitment to moral motives, Patricia's sensitivity may fade, her reflective capabilities may become rusty, and her virtuous dispositions may atrophy. In a collective context, amoral professionals may resist demanders' calls for higher standards, and push back against the types of institutions and reform initiatives that could help entrench those standards.

\footnotetext{
40 Arguably, these conditions may have been enhanced in historical cases where individual professionals enjoyed effective quasi-monopolies on service delivery, such as being the only lawyer or doctor in town.

41 Davis, 'Putting Your Profession First', above n 39; Davis, 'Thinking Like an Engineer', above n 14.

42 Myriad authors have observed the potentially caustic effect of monetary and material priorities on traditional values: see, eg, Kwame Anthony Appiah, The Honor Code: How Moral Revolutions Happen (Norton, 2010) 194.
} 


\section{SOCIAL, INSTITUTIONAL AND CONTEXTUAL SUPPORTS FOR SUPPLY AND CAPABILITIES}

This Part explores the elements of the ethics regime that can strengthen professionals' moral motives and capabilities. These elements include those people calling for ethics reform (demanders), the supports that can strengthen and activate moral qualities, and the initiatives and institutions that can deliver those supports.

\section{A Demanders}

'Demanders' comprise the groups calling for the development, consolidation or reform of the professional ethic so as to create high standards of conduct and competence. ${ }^{43}$

Paradigm demanders include the professionals' clients and prospective clients, who harbour a raft of vulnerabilities that professionals' fiduciary responsibilities work to mitigate. They also include third-party stakeholders, either as individuals or as a collective, who have a stake in whether the professional ethic is performed. Sometimes, professionals (or service-providers in an embryonic profession) themselves can count as demanders, as individuals can benefit - morally and materially - from being one member of a larger ethically-constrained collective.

Large organisational employers of professionals can also be demanders. ${ }^{44}$ Such organisations, in employing professionals, can take over many of the roles previously played by professional organisations..$^{45}$ Employers can become demanders as a low-cost way of encouraging high standards of work amongst their professionals, ${ }^{46}$ or simply because an internalised professional ethic correlates with professional 'effectiveness' as evaluated by clients and colleagues. ${ }^{47}$

Figure 1's ethics regime model shows why demanders can be so important to the development of the professional ethic. In various ways, demanders can exert pressure on all of the required capabilities. Their demands, whether voiced individually or collectively, can help raise the moral awareness of professionals even with limited sensitivity. Demanders can assist professionals' moral reflectiveness by offering input, floating improved ways of responding to archetypal situations, and describing potential morally-charged concerns from their own perspective. They can assist with the growth and relevance of certain

43 For further details on demanders, see Breakey, 'Supply and Demand', above n 7, 5-11.

44 That said, professional ethics can clash with larger organisational values, and the normal authority that employers can expect to wield over their employees, meaning that such organisations can also count as obstacles, or even strategic blockers, of professional ethics. Breakey and Sampford, 'Employed Professionals' Ethical Responsibilities', above n 19.

45 See, eg, in the context of the legal profession, John Flood, 'The Re-landscaping of the Legal Profession: Large Law Firms and Professional Re-regulation' (2011) 59 Current Sociology 507.

46 The role of excellence and its cost-effectiveness are discussed in Breakey, 'Wired to Fail', above n 37 , 74-5, and honour and its cost-effectiveness in Appiah, above n 42, 191-5.

47 In the context of law, see Hamilton and Monson, 'The Positive Empirical Relationship', above n 2. 
moral motives - such as by according social status and honours (relevant to Deserved Approbation) and by highlighting (and perhaps even provisionally withholding) privileges the profession enjoys in return for shouldering its ethical responsibilities (relevant to Covenant). Demanders can also facilitate institutions that nurture character and competence.

Demanders can exert these pressures on a micro, individual level. In cases where clients have enough awareness to recognise poor professional performance, they can vote with their feet and their wallets, driving business away from poor-performing professionals (or even entire poor-performing professions). Individual demanders can also be more assertive with their service providers about their expectations, perhaps employing contractual protections to ensure the delivery of proper service. In cases where prospective clients are faced with a range of competing professional organisations, they can educate themselves about the specific standards offered by each. ${ }^{48}$

Demanders might also aggressively pursue legal options, whether through civil or criminal law, or through consumer complaint mechanisms. They may do so as individuals, or through class-action civil litigation.

As a collective, demanders can apply political pressure to politicians and regulators. They may engage in consumer advocacy processes, or use social media or NGOs of various sorts to help lobby government and publicise their concerns. Even spontaneous outbursts of social outrage and blame, such as large rallies and protests, can help shift the larger context in which professional malfeasance takes place. ${ }^{49}$

Demanders can also focus their attentions on the institutions that encourage ethical standards in professionals. The most obvious targets here are professional organisations, and training and educational organisations. But, in some circumstances, exerting pressure on government regulators can motivate servicesectors to improve standards to forestall potentially intrusive state microregulation. Similarly, just as large organisational employers shoulder many of the normal tasks of professional organisations, they can face the brunt of demanders' ire at poor standards.

But what specific types of supports and initiatives should demanders and reformers facilitate? The remainder of this Part describes an array of strategies to target particular deficiencies in the existing ethics regime.

\section{B Supports and Initiatives for Capabilities and Moral Motives}

As this section details, social structures and institutional processes can impact decisively on the presence and strength of professionals' moral qualities, and on

\footnotetext{
48 Laypeople can struggle to differentiate between genuinely professional practitioners/organisations and other service-providers: see, eg, Aegis J Frumento and Stephanie Korenman, 'Professionalism and Investment Advisers' (2013) 14(1) Journal of Investment Compliance 32.

49 The recent public response to the 'Panama Papers' leaks provides an example, where the scandal leaked into wider conversations about the regulation of global finance, banking and the legal and accounting professions.
} 
their effective operation in any given situation. ${ }^{50}$ Indeed, institutional resources can be so powerful that - in some cases at least - they can all but obviate the need for a specific capability.

Institutions can impact beneficially on moral capabilities in several different ways. (Moral motives prove somewhat different to capabilities: I discuss these in Part IV(B)(3) below.) An institution can empower our professional, Patricia, by:

- Cultivating a moral capability: The institution strengthens and develops Patricia's sensitivity, reasoning, character or competence. Alternatively, it empowers the capability so as to expand its operation into new domains. In either case, the institutional process of cultivation works to alter Patricia herself, and her intrinsic qualities.

- Protecting a moral capability: The institution shields Patricia's existing capabilities from obstacles (such as those noted in Part III above) that might otherwise degrade the capability's strength or functioning.

- Facilitating a moral capability: The institution alters the external context or decision-making environment so that Patricia's existing capabilities prove sufficient to empower her moral action at an appropriate standard. The limit case of facilitation occurs when the institutional process is so substantial it can almost replace Patricia's need for the capability altogether.

Generic supports are activities, factors or processes that impact felicitously on an array of capabilities and/or moral motives. I provide two examples.

First, institutional factors within a professional practice (or within the practices of an employing large organisation) might routinely place professionals in direct, face-to-face meetings with their clients. These interactions can serve multiple moral purposes. In terms of sensitivity, the interactions allow clients to directly air concerns with the professional, facilitating the professional's awareness of relevant moral factors. In terms of reflectiveness, the interactions can furnish the decision-making professional with new information and alternative moral perspectives. In terms of moral motives, the face-to-face meetings can create clearer lines of responsibility (avoiding responsibility being muddled over myriad task-holders) and create greater opportunities for the operation of natural empathy, which can serve as a fillip to many moral motives.

Second, ethics training, such as through a university or other formal professional training regime, can raise sensitivity by showcasing the various considerations that can arise, and the usual stakeholders (and demanders) whose interests warrant respect in professional work. Ethics training can improve reasoning by showing how broad moral principles can, when applied to the specific professional context, give rise to specifiable duties, and how tensions between apparently conflicting ethical obligations can be navigated. While

50 This section's explanation of various institutions and initiatives is, of course, not meant to be comprehensive. Rather, the intention is merely to show how particular initiatives and supports can improve the functioning of specific parts of the process undergirding moral action. 
actually cultivating new moral motives might prove difficult, ${ }^{51}$ showing how specific codes follow from widely held principles may activate the student's existing moral motives in their application to core professional obligations.

\section{Supports for Professionals' Moral Sensitivity}

Patricia's moral sensitivity benefits from the availability and accessibility of fine-grained, detailed professional codes of conduct. ${ }^{52}$ These codes are especially helpful when taught through effective educational processes and promulgated by the professional organisation. ${ }^{53}$ Such codes cultivate sensitivity by alerting Patricia to the types of factors that should be ringing her ethical alarm bells and prompting her to stop and reflect. This effect is particularly powerful for codes of conduct that describe the paradigm threats and potential conflicts of interest that set the stage for looming ethical failures. (The accounting profession has long employed such codes.) These codes improve sensitivity by alerting Patricia to morally relevant changes in her context that might otherwise slip by unnoticed.

Mentoring and supervised work, where potential ethical concerns can be highlighted by experienced professionals, also cultivate moral sensitivity though with the additional benefit of seeing how the concerns arise in an actual work context.

The publicising and accessibility of the decisions of professional tribunals or review boards can cultivate sensitivity by providing examples of common types of failures. ${ }^{54}$ Publicising the acts of ethical exemplars, such as by bestowing professional honours and awards, can fulfil a similar process, but this time heightening sensitivity to aspirational standards, rather than disciplinary rules.

The institutional requisite for most of these initiatives is a strong and proactive professional association, capable of developing and promulgating finegrained codes, facilitating mentored and supervised work, and publishing examples of ethical failure and success. A large organisational employer can also take on many of these tasks. Employers also have the important capacity to develop scripts for dealing with difficult and complex tasks. These scripts can establish ethical steps (such as obtaining clients' informed consent before proceeding), or include decision-making nodes that instruct the professional to stop and scan for ethical issues. ${ }^{55}$

Finally, interpersonal traits such as being approachable, non-judgmental and open to constructive criticism, heighten Patricia's sensitivity by allowing other

51 For discussion, see Hamilton and Monson, 'Legal Education's Ethical Challenge', above n 2; Hugh Breakey and Charles Sampford, 'Reflection: Educating Ethical Lawyers' in Charles Sampford and Hugh Breakey (eds), Law, Lawyering and Legal Education: Building an Ethical Profession in a Globalizing World (Routledge, 2017) 203.

52 'Disciplinary codes', as distinct from 'aspirational codes': see Charles Sampford, 'Institutionalising Public Sector Ethics' in Noel Preston (ed), Ethics for the Public Sector: Education and Training (Federation Press, 1994) 14. See also Rest, 'Background: Theory and Research', above n 2, 9.

53 While many ethical issues cannot simply be tested in an exam situation, the use of 'un-flagged' ethical questions can test for (and so encourage the study of) ethical sensitivity.

54 Kenneth L Carper, 'Engineering Code of Ethics: Beneficial Restraint on Consequential Morality' (1991) 117 Journal of Professional Issues in Engineering Education and Practice 250, 256.

55 Gioia, above n 11, 388. 
actors (including peers, colleagues, clients and subordinates) to alert her to her limitations or failings. Such traits are 'interpersonal' in the sense that, although they are personal qualities held by the professional, they only work in tandem with a social environment that includes other people willing to offer instruction and food for consideration.

\section{Supports for Professionals' Moral Reflectiveness}

The cultivation of moral reflectiveness can occur through several means.

University courses that focus explicitly on wielding philosophical moral theories can be helpful, as can courses in critical thinking and informal logic. ${ }^{56}$ Empirical evidence suggests that justice-based reasoning (one type of moral reflectiveness) is improved through tertiary studies generally. ${ }^{57}$ Moral reflectiveness includes the knowledge of a professional's options in a given case. This capability may be developed in the professional through direct instruction, personal research, peer learning or hands-on experience.

Patricia's access to an 'advice hotline' may allow her to overcome any personal shortcomings in, or situational constraints on, her moral reflectiveness. Of course, in such a case, Patricia will still need moral sensitivity to know when to ask for advice, and will need moral motives and character to put the advice into practice. But the specific task of working out what the (perhaps subtle and conflicting norms of) professional ethics requires in the particular situation can be out-sourced to the professional advice service..$^{58}$

Initiatives that cater for work-life balance, enhance the quality of work, and support professionals' general wellbeing, will help protect Patricia's reasoning faculties from obstacles like stress, substance-abuse, and extreme time-pressures that can curtail the space required for moral reflection.

In terms of facilitation, institutional practices that require the recording of morally salient facts can help activate moral reflectiveness. They do so by prompting Patricia to picture how her actions might look to impartial observers (especially other professionals) who may later have cause to review such records.

\section{(a) Social Deliberation}

Patricia's capacity to constructively engage in moral deliberation with others (especially peers and experienced colleagues) can be important. After all, one of the most widespread responses to being faced with real-world, ethical dilemmas is simply to seek the advice and thoughts of other respected and experienced people, drawing in alternative moral perspectives from inside and outside one's work environment. Social deliberation can be facilitated through institutional

56 Hugh Breakey and Charles Sampford, 'Reflection: Philosophy in Legal Education - Promises and Perils' in Hugh Breakey and Charles Sampford (eds), Law, Lawyering and Legal Education: Building an Ethical Profession in a Globalizing World (Routledge, 2017) 72; Breakey and Sampford, 'Educating Ethical Lawyers', above n 51.

57 Rest, 'Morality', above n 2, 592; Rest, 'Background: Theory and Research', above n 2, 15.

58 Patricia will need to be able to follow the adviser's line of reasoning. Unless she understands how her moral motives undergird the specific actions she is required to perform, then she would not be acting morally (as Part I defined that term). 
procedures - but it can also be fuelled by the professional's personal desire to deliberate with others in search of a shared understanding. Such desires can be moral in themselves; they can include, for example, the wish to show respect to others by engaging in constructive and inclusive dialogue, acknowledging the sincerity of the alternative positions they may advance, and so on. ${ }^{59}$ As well as Patricia's own interpersonal drives for deliberation, this practice requires available colleagues and mentors, and other people that can work as 'sounding pads' for Patricia to bounce her ideas off, or to play 'devil's advocate'.

Social deliberation suffers from its own obstacles and limitations. The largest obstacle to deliberation is isolation. Depriving the professional of accessible peers, and also of friends and family who may be helpful in thinking through difficult ethical questions, can arrest this process before it even begins. For this reason, networking processes and other social interactions, whether through the professional organisation or a large organisational employer, can facilitate interaction with peers and colleagues, and help overcome the perils of isolation.

Unfortunately, the wrong sort of social deliberation can impede moral reflectiveness. Heath argues that in social environments where people routinely employ and accept self-serving rationalisations for exception from ethical standards ('neutralising excuses'), individuals are more likely to reason their way to specious justifications of their ethical (and even legal) breaches. ${ }^{60}$ Equally though, moral reflectiveness performed in scrupulous isolation carries its own dangers. ${ }^{61}$ It therefore may be that the best results are garnered by ethics regimes that facilitate both processes: individual moral reflectiveness and social deliberations.

\section{Supports for Professionals' Moral Motives}

While capabilities can be cultivated, protected or facilitated by institutional initiatives, the picture with moral motives is more complex. Institutional processes can aim to:

- Cultivate moral motives: Cultivation involves strengthening an existing value, or creating an entirely new value. Either way, there is a definitive change in Patricia's moral motives.

- Activate moral motives: Activation does not aim to change Patricia's moral motives, but simply to ensure that an existing moral motive is psychologically activated in a certain context. For example, requiring a public oath of professionalism can attach existing moral motives of honesty and integrity to the professional ethic. ${ }^{62}$ Alternatively, structuring professional-client interactions in a constructive and face-to-face manner can encourage an empathic response capable of activating moral motives

59 Martin Benjamin, Splitting the Difference: Compromise and Integrity in Ethics and Politics (University Press of Kansas, 1990), 36-43; Hugh Breakey, 'Compromise despite Conviction: Curbing Integrity's Moral Dangers' (2016) 50(3) Journal of Value Inquiry 613.

60 Heath, above n 20, 604.

61 See Luban, above n 30; Haidt, above n 4, 105.

62 Carper, above n 54, 256. 
of beneficence and non-harm. In both examples, Patricia's existing moral motives are activated by triggering events.

- Reform moral motives: Reform changes the way the existing moral motive is understood, aiming to keep its motivational strength, but altering its content. ${ }^{63}$ The excision of professional restraints on advertising in the United States (following a United States Supreme Court judgment) provides an example: the code itself was not expunged, but sections were reformed in an arguably pro-social direction. ${ }^{64}$

- Protect moral motives: Protection involves defending an existing set of moral motives from obstacles that impede their functioning. For example, after describing the various means by which lawyers' ethics are eroded, David Luban suggests several protective efforts, including that lawyers beginning their careers take the time to write down the standards they want to live up to - the 'lines' they will never cross. Setting down in concrete the 'lines' they will never cross, can give them a sense of perspective years later when they find themselves slipping into dangerous territory. ${ }^{65}$

- Facilitate moral motives: Facilitating moral motives involves changing the external context or decision-making environment so that existing value (in terms of presence, felt-importance and content) proves more material in Patricia's decision-making. For example, skewed evaluative metrics (and the resulting incentives) inside an organisation can mean that Patricia's career path and social standing within the organisation, presses against her moral motives. ${ }^{66}$ Aligning the organisation's metrics with the professional's moral motives may not, in itself, strengthen those motives - but it does, at least, limit the internal forces opposed to them.

Within the above bullet-points, I provided examples of activating, reforming, protecting and facilitating Patricia's moral motives - but not of cultivating moral motives. There is a reason for this omission. The deliberate creation of genuinely new moral motives, or the strengthening of nascent moral motives, is not a task that can be easily fulfilled by discrete initiatives. ${ }^{67}$ People's moral motives are created and sustained by a wide array of forces, both internal and external, cultural and psychological, social and pragmatic, cognitive and emotional sometimes built up by communities over decades or even centuries. ${ }^{68}$ Such moral

63 Some striking examples of reform are provided by Appiah, who notes how the standards dictated by honour shifted in responses to social ridicule and activism: Appiah, above n 42. See especially at 47.

64 See David K McGraw, 'A Social Contract Theory Critique of Professional Codes of Ethics' (2004) 2 Journal of Information, Communication and Ethics in Society 235, 239.

65 Luban, above n 30, 308.

66 On the clash between clumsy metrics and occupational virtues, see Breakey, 'Wired to Fail', above n 37.

67 See Breakey, 'Supply and Demand', above n 7, 14.

68 See, eg, Breakey, 'Same Duties Different Motives', above n 5; John Stuart Mill, Utilitarianism (Hackett, first published 1861, 2001 ed) 29; Friedrich Nietzsche, On the Genealogy of Morals (Douglas Smith trans, Oxford University Press, 1996) [trans of: Zur Genealogie der Moral (first published 1887)]; David B Wong, Natural Moralities: A Defense of Pluralistic Relativism (Oxford University Press, 2009); Haidt, above $\mathrm{n} 4$. 
motives are not usually amenable to deliberate, external manipulation - meaning that strategies of activation, reform, protection and facilitation will often prove to be more productive ways of improving ethical performance.

That said, key institutions - especially when they enjoy strong leadership can make a difference. Vibrant and pro-active professional organisations, and also large organisational employers, can foster a sense of collective identity and role-identification with like-minded peers. Going through a dialogic process with the organisation's members to develop new ethical standards and goals can help build a sense of ownership over, and shared identity in, the professional ethos. ${ }^{69}$ This sense of ownership applies especially to aspirational declarations and standards. We saw earlier that a fine-grained 'disciplinary' code can help heighten awareness, and inform reasoning processes. However, such codes can seem removed from the underlying principles and goals that animate them. ${ }^{70}$ The development of aspirational codes that inspire professionals through their invocations of high standards, vital social functions, and lofty aims can cultivate (strengthening and even creating) professional's moral motives.

All that said, there is reason to focus reform efforts on moral capabilities rather than moral motives. Accusations that professionals lack moral motives can put them on the defensive, and make them resist reform efforts. Such an approach can foreground questions like: 'Who did the wrong thing?' rather than: 'How can the system be improved?'. Conversely, focusing reform efforts on improving capabilities involves empowering professionals. It assumes the professionals want to succeed in their moral roles - and this assumption can help enrol the professionals in reform efforts.

\section{Supports for Professionals' Moral Character}

Since the very beginnings of the study of virtue and character - whether by Aristotle in Athens or by Confucius in China - thinkers have considered the ways that character can be cultivated by deliberate self-development or inculcation in supportive environments. ${ }^{71}$ Over time, and through attentive practice, enduring character traits can be constructed and consolidated by individuals and institutions. In modern times, similar themes have been explored by psychologists speaking of all-purpose traits like emotional intelligence and egostrength. Theorists have also explored the possibilities of building these traits through education and inculcation - including that of professionals. ${ }^{72}$ Able to structure its students' activities over years on end, university education can prove a pivotal player in the development of professional virtues. Universities can employ an array of practices - in terms of course content, teaching methods and

69 See Sampford, 'Institutionalising Public Sector Ethics', above n 52; Carper, above n 54.

70 Sampford, 'Institutionalising Public Sector Ethics', above n 52; Daniel E Wueste, 'Promoting Integrity Integritively: Avoiding the Scylla and Charybdis of Abdication and Zealotry' in Michael Shwartz and Howard Harris (eds), Achieving Ethical Excellence (Research in Ethical Issues in Organizations vol 12, Emerald Group Publishing, 2014) 5.

71 See Aristotle, above n 6; Confucius, above n 6.

72 See, eg, James, above n 12; Rest, 'Teaching of Ethics', above n 2. 
even faculty culture - that encourage the development of professional virtues. ${ }^{73}$ Once outside the university, new professional virtues can be inculcated through other means, such as immersion in team environments - for example, in clinical treatment of patients - where the appropriate emotional responses are expected and valued by the team, and become ingrained in the aspiring professional.

Moral character can also be facilitated. A supportive, understanding social network, consisting of family, professional peers, colleagues, and friends in the wider society, can encourage the professional to have the confidence to act on their moral motives. More specifically, the existence and enforcement by the professional organisation of standardised ethics gives strength and confidence to those professionals asserting their ethics. They can do so with the confidence of knowing that a new professional cannot simply be employed who will give the client or employer the desired 'answer' ${ }^{74}$

\section{Social Supports for Professionals' Moral Competence}

For professionals, moral competence includes professional expertise and interpersonal skills. The need for institutions and processes to furnish the professional with expert knowledge is well-known, and occurs through university education, internships and supervised work, studying for national exams, and life-long learning practices.

Competence in performing the challenging interpersonal interactions demanded by professional ethics also can be cultivated. Both universities and work experience - and especially combinations of the two in terms of mentoring, traineeships, internships and other forms of 'work-integrated learning' 75 - can provide vital learning experiences. Students and aspiring professionals can improve in interviewing skills, listening techniques, negotiation strategies, delivering constructive criticism, giving whole-of-business advice, and more. Still, in terms of such skills as they occur in concrete professional work, there is perhaps no substitute for years of experience, learning from the successful strategies of others, honing one's skills through trial and error, and other forms of self-directed learning.

Help-seeking behaviours and strategies provide a further example of interpersonal capabilities that help professionals make the most of the social supports around them. Patricia's willingness to ask for others' advice and assistance can expand the available options open to her, improving her decisionmaking and ultimate outcomes. The same interpersonal qualities can help her in the judgment stage: by not being afraid to ask for help, Patricia can enhance mentoring and collegial deliberation.

73 See, eg, Hamilton and Monson, 'Legal Education's Ethical Challenge', above n 2; Breakey and Sampford, 'Educating Ethical Lawyers', above n 51.

74 Davis, 'Thinking Like an Engineer', above n 14. On employers 'shopping around' for desirable professional answers, see, eg, Charles Sampford, “"Get New Lawyers!"” (2003) 6 Legal Ethics 85; Charles Sampford, 'More and More Lawyers but Still No Judges' (2005) 8 Legal Ethics 16.

75 See Mark Brimble et al, 'Collaborating with Industry to Enhance Financial Planning and Accounting Education’ (2012) 6(4) Australasian Accounting Business and Finance Journal 79. 


\section{Supports for Professionals' Moral Reflectiveness (Review)}

In the review stage, ongoing educational and training processes can help provide Patricia with space and resources for learning lessons from her previous moral successes and failures. Well-designed Continuing Professional Development (CPD) courses on professional ethics presents one means of filling this role, as do higher degree learning opportunities, where Patricia is able to reflect on her new learning on the basis of her past experiences.

\section{The Flipside of Capability: Availability of Nuanced Moral Options}

For Patricia to behave ethically, and effectively, she must have a feasible ethical alternative open to her. Some aspects of this factor may be a function of her personal capabilities. One part of moral reflectiveness involved being able to learn about the available courses of action - or to construct them through strategic nous or lateral thinking. As well, the compass of the available alternatives depends on Patricia's character and competence, in the sense that certain ethical alternatives might require less courage and interpersonal skill to perform. More demanding alternatives may only be open to those with higher levels of character and competence.

Even so, the availability of feasible alternatives remains primarily a function of the professional's environment. This means that, when 'ethical failures' occur, sometimes the best response may be to improve the options available to professionals, rather than to improve the professionals themselves.

The phenomenon of whistleblowing presents an apt example of a morallyloaded situation plagued by a paucity of good options. Patricia may be faced with complicity in an ethically-worrisome policy, and may fail in her efforts to shift that policy through standard lines of workplace communication and authorisation. ${ }^{76}$ If so, her only recourse may be to expose the wrongdoing through leaking damning evidence to the public. But such whistleblowing is a notoriously risky endeavour - it possesses so many personal and professional risks (not least that of employer retaliation) that many ethicists consider it a supererogatory action. ${ }^{77}$ That is, while heroic and courageous, whistleblowing is not something that can be morally demanded of an employee. The personal costs are simply too high.

In such a case, a reformer's best response will not be to work out ways of improving Patricia's moral motives or capabilities to impel her to follow through on blowing the whistle. Instead, a better response would be to improve the extent and quality of Patricia's alternatives, such as by creating official 'internal whistleblowing' mechanisms that allow serious wrongdoing to be addressed outside ordinary lines of inter-organisation communication and authority - but without the public damage to the organisation's brand, and the ensuing risks to the professional's career.

76 On a complicity account of whistleblowing, see Michael Davis, 'Whistleblowing' in Hugh LaFollette (ed), The Oxford Handbook of Practical Ethics (Oxford University Press, 2005).

77 See, eg, Damian Grace and Stephen Cohen, Business Ethics (Oxford University Press, $5^{\text {th }}$ ed, 2013), 21931. Cf Davis, above n 76. 
When developing options for moral responses, professionals thus benefit from the existence of:

- Graduated options that allow a nuanced response that is not 'over the top' in relation to the seriousness of the issue;

- Backup responses that allow the professional to take more serious measures if initial measures fail;

- Viable options that allow a moral response without requiring great courage (moral character) or rare diplomacy (moral competence), and that do not require excessive self-sacrifice and personal risk.

\section{OVERALL REFORM PROCESS}

We are now in a position to expand the earlier flowchart of the moral process.

Figure 3's flowchart has grown in complexity - but by expanding the elements through which principled moral action can occur, demanders and reformers have more institutions, initiatives and supports they can use to facilitate this desired result. ${ }^{78}$

Summing up, strategic ethical reform can occur through the following stages:

Diagnosis: Where does the problem lie in the overall process? ${ }^{79}$

- Does the problem lie in the working of a personal or interpersonal capability?

- Does the problem lie in the working of personal moral motives? Specifically, is the problem the weakness of the moral motives, their wrongful content, or their failure to activate in a specific context?

- Does the problem lie in the environmental qualities of the existing institutional context?

Reform strategies: What are the most promising reform solutions?

If the problem lies in a personal or interpersonal capability, then the following questions arise:

- If the problem is a lack of the capability, what are the options for cultivating it?

- If the problem is a powerful obstacle to the capability's functioning, what are our options for protecting it?

- If the problem is the exercise of the capability in the existing environment, what are our options for facilitating it?

78 In Figure 3, I have altered the wording on several of the capabilities to include 'personal', so to distinguish those qualities from interpersonal capabilities and environmental qualities.

79 Reformers need not always perform a rigorous diagnosis. If an initiative can be cost-effectively implemented, then it might be worth moving ahead with implementation just to shore up the particular capability it facilitates. 


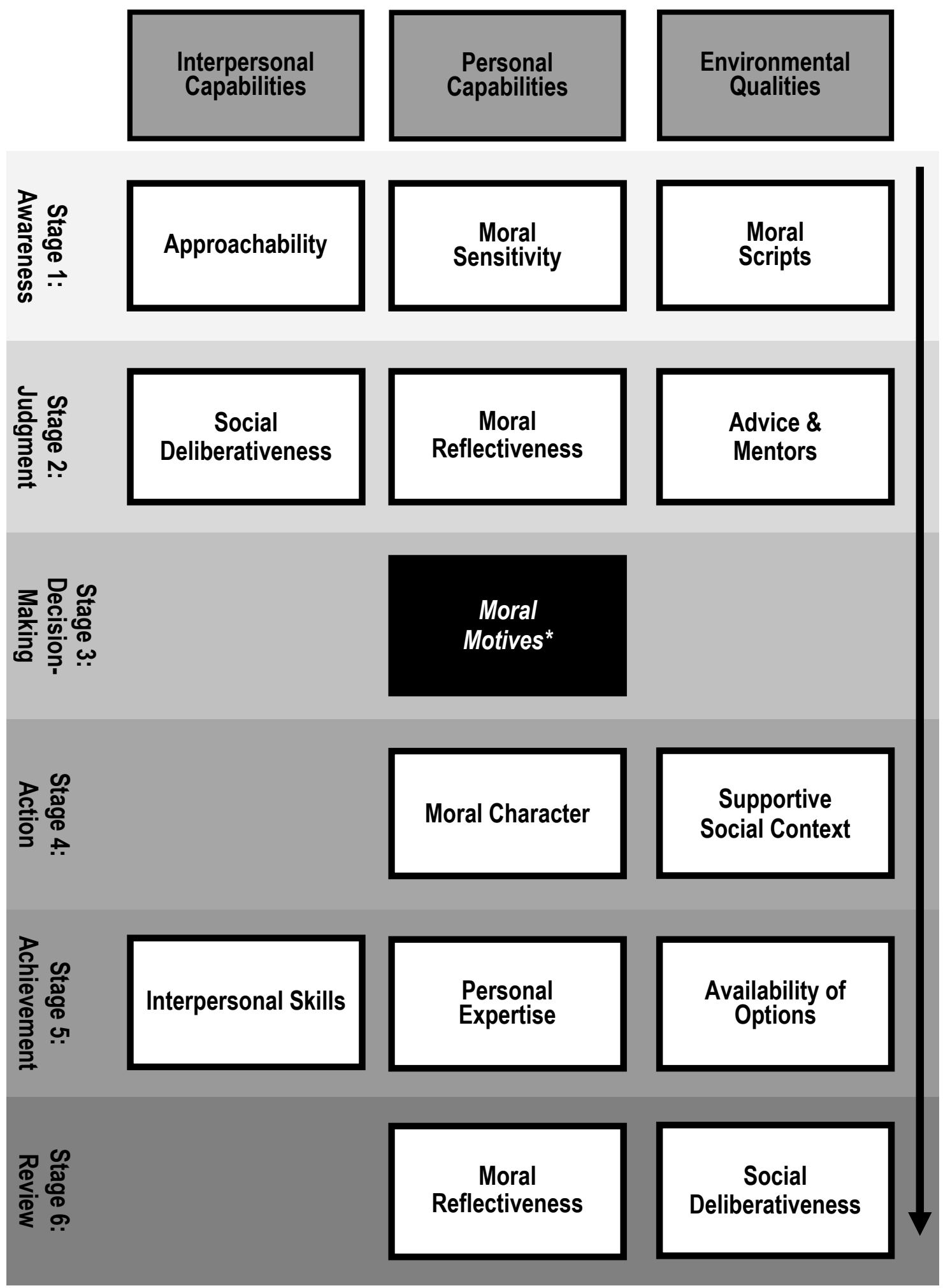

*Moral Motives are values, not capabilities.

Figure 3: Flow-chart of social and institutional elements in the moral process 
If the problem lies in the operation of a professional's personal moral motives, then:

- Does the professional already possess moral motives that can be activated, reformed, protected or facilitated?

- Are there feasible options for cultivating moral motives, either by strengthening existing moral motives or constructing new ones?

If the problem lies in the qualities of the environment in which the professional acts, then:

- Are there ways of improving the set of options available to the professional, allowing them to make better choices?

- Can the context be made more supportive, such as by changing incentive structures, or encouraging networking with other professionals?

Mustering resources: In making the above judgments about available reform options, key questions include:

- Who are the demanders? Which parts of the community can be relied upon to invest resources, time and attention in facilitating these reforms? How can their voices be consolidated, maintained and amplified?

- Are there any blockers? Which parts of the community can be expected to strategically resist reform efforts?

- What institutions exist, through whose mediation and reform, improvements can be made? Or do new institutions need to be constructed?

To conclude, this article has developed an ethics regime model, where demanders, institutions, initiatives and supports are brought to bear on every element of the process that leads to principled moral action. These elements include the qualities foregrounded by moral psychology, encompassing moral sensitivity, moral reflectiveness, moral motives, moral character and moral competence. But they also include other, more social and institutional elements, incorporating interpersonal capabilities of openness and deliberativeness, and environmental factors like access to advice and mentors, a supportive social context, and improved moral options. Reform measures can not only aim to create and strengthen these qualities, but also include measures designed to activate, reform, protect and facilitate them. Taken together, the ethics regime model allows demanders, reformers and regulators to diagnose, and even to target with focused reform measures, the wide array of deficiencies that can impair high standards of professional ethics. 